\title{
Subdural Hemorrhage Mimicking Relapse in a Patient with Multiple Sclerosis
}

\author{
(D) Mehmet Fatih Yetkin, (D) Merve Akcakoyunlu, (D) Mehmet Fatih Gol, (D) Meral Mirza \\ Erciyes University Faculty of Medicine, Department of Neurology, Kayseri, Turkey
}

\section{Abstract}

Multiple sclerosis (MS) is an immune-mediated disease of the central nervous system, which is more common in young adults and can present with various clinical manifestations. The emerging neurological findings in the course of MS are often considered as relapses; however, neurological deterioration may have other treatable causes than relapses. No data are indicated in the increased frequency of the overall hemorrhagic stroke in individuals with MS, thus the coexistence of MS and subdural hematoma has been rarely reported. This study presents a 49-year-old male patient with a subdural hematoma that mimics a relapse. Recently emerging neurological symptoms in the course of MS frequently indicate a new demyelination event; however, emerging neurological symptoms may have other treatable causes besides relapse, especially in the presence of red flags such as headaches.

Keywords: Demyelinating disorder, multiple sclerosis, subdural chronic hematoma

\section{Introduction}

Multiple sclerosis (MS) is a chronic and persistent inflammatory demyelinating disease of the central nervous system that is pathologically characterized by areas of inflammation, demyelination, axonal loss, and gliosis (1). Recently developing neurological symptoms are often considered as a new active demyelination episode in the course of relapsing-remitting MS, without infection or fever (2). Accurate identification of the demyelinating attack in the patient's history or objective detection by examination is critical in MS diagnosis and treatment. Red flags were defined, such as headache, acute or subacute cognitive impairment, and steroid unresponsive neurological deficit, which represent an atypical relapse (3). A distinction of the relapse mimics from true demyelination episodes requires expertise and rigorous clinical judgment. The most common disorders that are mistaken with MS are reported to be functional neurological disorders and migraine (4). Additionally, cerebrovascular disorders may mimic relapse, and subdural hemorrhage (SDH) is a surgically treatable cause of neurological deterioration in persons with MS (pwMS).
Reported herein is a case of SDH that mimics relapse, which is initially treated with high-dose methylprednisolone.

\section{Case Report}

A49-year-old male patient was admitted to our clinic 10 years ago with dizziness and gait impairment. The patient was diagnosed with MS based on physical examination, neuroimaging (Figure 1), and cerebrospinal fluid examination. After his diagnosis, he was treated with interferon $\beta 1 \mathrm{~b}$; however, he experienced approximately two relapses annually, which are mainly motor and cerebellar functions. In the fourth year of treatment, he was admitted again with gait impairment complaints. The physical examination revealed bilateral $3 / 5$ muscle strength on the lower extremity and $4 / 5$ on the bilateral upper extremity. Further, deep tendon reflexes were generalized hyperactive, and the bilateral Babinski sign was positive. The expanded disability status scale score was 3 . This new neurological function loss was evaluated as an attack and intravenous methylprednisolone treatment was initiated. However, despite the 3-day course of pulse steroid treatment, the patient's clinical findings did not improve. Additionally, he began to experience mild to moderate

Address for Correspondence: Merve Akcakoyunlu, Erciyes University Faculty of Medicine, Department of Neurology, Kayseri, Turkey Phone: +90 5454843256 E-mail: merveakcakoyunlu@hotmail.com ORCID-ID: orcid.org/0000-0003-3311-3602

Received: 05.10.2021 Accepted: 10.11.2021

${ }^{\circ}$ Copyright 2021 by the Journal of Multiple Sclerosis Research published by Galenos Publishing House. 
headache that was not previously present. Brain magnetic resonance imaging was performed because of the red flags for neurological deterioration, which revealed a bilateral subacute SDH (Figure 2).

SDH was successfully treated with bilateral burr-hole (Figure 3). The patient reached the previous neurological stage after the operation. During the 6-year follow-up period after SDH, SDH was not observed again; however, the secondary progression of MS continued. The treatment was first shifted to fingolimod and subsequently to ocrelizumab upon progression.

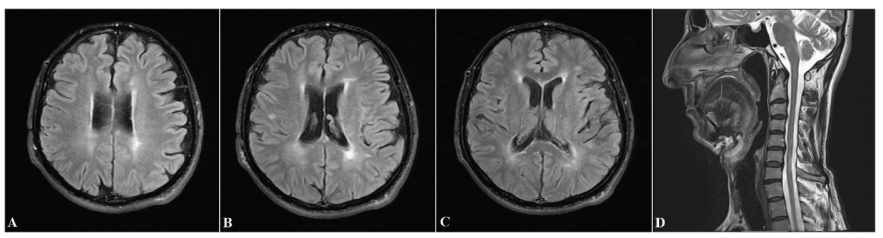

Figure 1. A, B, C. Periventricular, subcortical, and deep white matter hyperintense lesions are seen on the fluid-attenuated inversion recovery (FLAIR) images. D. T2-weighted images reveal hyperintense lesions and a slight volume loss of the cervical spinal cord

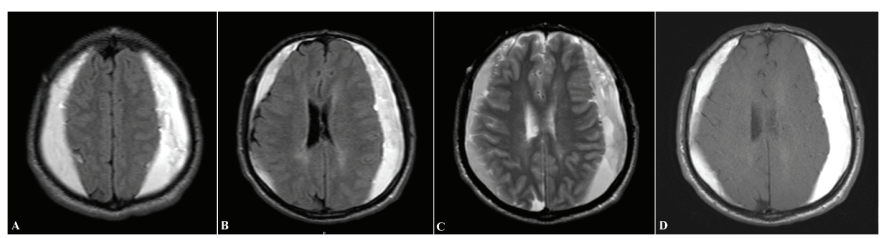

Figure 2. A, B, C. FLAIR and T2-weighted images reveal hyperintense signal in the subdural space with slight hypointense areas. D. T1-weighted images reveal hyperintense signal in the subdural space. Additionally, effacement is observed in both lateral ventricles, which is more prominent on the left side

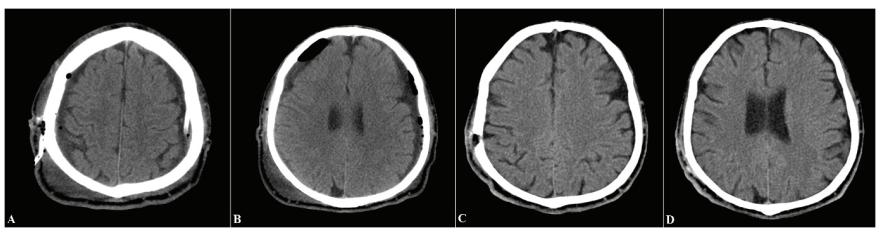

Figure 3. A, B. Early postoperative computed tomography (CT) images reveal air intensities in the subdural space with an indwelling drain. C, D. CT images one month after operation reveal complete improvement in the subdural hemorrhage

\section{Discussion}

To our best knowledge, this is the fourth case of SDH ever reported in a pwMS. SDH is a common disease characterized by the abnormal collection of blood products in the subdural space (5). Individuals with MS may clinically present with monofocal or multifocal symptoms. Typical symptoms of MS include unilateral optic neuritis, focal supratentorial syndrome, focal brainstem or cerebellar syndrome, partial myelopathy with atypical presentations being bilateral optic neuritis, complete ophthalmoplegia, complete myelopathy, encephalopathy, headache, altered consciousness, meningismus, or isolated fatigue (2). The first case of SDH in a pwMS was reported by Harding (6) who experienced SDH associated with a lumbar puncture. In addition, Magro et al. (7) reported bilateral subacute subdural hematoma following implantation of intrathecal drug delivery device in a pwMS. The first study about spontaneous SDH was published by Flohil et al. (8) who described two cases of unilateral SDH without trauma or headache. As in our case, they were initially misinterpreted as a relapse because of the MS history of patients.

The risk of SDH in pwMS can be explained by several possible mechanisms. Brain atrophy is a well-known risk factor for SDH (5). In addition, stretching the bridge veins secondary to brain volume loss, which inevitably arises in the course of the disease, may increase the risk of SDH in MS. Moreover, interferon $\beta 1 \mathrm{~b}$ treatment was reported to affect the platelet count and function causing a tendency to bleed (9). In an early report, Pakulski et al. (10) reported severe vaginal bleeding probably associated with interferon $\beta 1$ b. Subsequently, Perlman and DiMarco (11) reported postmenopausal bleeding in a pwMS receiving interferon $\beta 1$ b probably due to elevated estrogen levels with unknown mechanisms. Although pwMS were reported to have an increased risk of developing any type of stroke compared with the general population, increased frequency of hemorrhagic stroke compared to matched controls were not found (12). Contrarily, PwMS have increased balance issues and are more likely to fall, which may lead to head trauma (5). The risk of developing SDH in a pwMS appears to have increased for several reasons, but few reports are available in the literature.

This discordance suggests the underdiagnosis of SDH in pwMS. In addition, the elevated risk of falling due to the loss of balance and vision in pwMS increases the risk of SDH.

Consequently, the third case with spontaneous SDH and first bilateral SDH in pwMS was presented in this study to attract attention to a treatable cause of relapse mimic. Recently emerging neurological symptoms in the course of MS frequently point to a new demyelination event; however, neurological deterioration should be kept in mind to also have different reversible causes, such as $\mathrm{SDH}$, especially in the presence of red flags, such as headache and unresponsiveness to steroid treatment.

\section{Ethics}

Informed Consent: Consent form was filled out by all participants.

\section{Authorship Contributions}

Surgical and Medical Practices: M.F.Y, M.F.G., M.M., Concept: M.F.Y, M.F.G., Design: M.F.Y., M.M., Data Collection or Processing: M.F.Y., M.M., Analysis or Interpretation: M.F.Y., M.A., Literature Search: M.F.Y., M.A., Writing: M.F.Y., M.A. 
Conflict of Interest: No conflict of interest was declared by the authors.

Financial Disclosure: The authors declared that this study received no financial support.

\section{References}

1. Filippi M, Bar-Or A, Piehl F, Preziosa P, Solari A, Vukusic S, Rocca MA. Multiple sclerosis. Nat Rev Dis Primers 2018;4:43.

2. Thompson AJ, Banwell BL, Barkhof F, Carroll WM, Coetzee T, Comi G, Correale J, Fazekas F, Filippi M, Freedman MS, Fujihara K, Galetta SL, Hartung HP, Kappos L, Lublin FD, Marrie RA, Miller AE, Miller DH, Montalban X, Mowry EM, Sorensen PS, Tintoré M, Traboulsee AL, Trojano M, Uitdehaag BMJ, Vukusic S, Waubant E, Weinshenker BG, Reingold SC, Cohen JA. Diagnosis of multiple sclerosis: 2017 revisions of the McDonald criteria. Lancet Neurol 2018;17:162-173.

3. Yamout B, Sahraian M, Bohlega S, Al-Jumah M, Goueider R, Dahdaleh M, Inshasi J, Hashem S, Alsharoqi I, Khoury S, Alkhawajah M, Koussa S, Al Khaburi J, Almahdawi A, Alsaadi T, Slassi E, Daodi S, Zakaria M, Alroughani R. Consensus recommendations for the diagnosis and treatment of multiple sclerosis: 2019 revisions to the MENACTRIMS guidelines. Mult Scler Relat Disord 2020;37:101459.

4. Solomon AJ, Naismith RT, Cross AH. Misdiagnosis of multiple sclerosis: Impact of the 2017 McDonald criteria on clinical practice. Neurology 2019;92:26-33.
5. Sambasivan M. An overview of chronic subdural hematoma: experience with 2300 cases. Surg Neurol 1997;47:418-422.

6. Harding AE. Subdural haematoma in two patients with chronic neurological disorders. Br Med J (Clin Res Ed) 1984;288:1986-1987.

7. Magro E, Remy-Neris O, Seizeur R, Allano V, Quinio B, Dam-Hieu P. Bilateral subdural hematoma following implantation of intrathecal drug delivery device. Neuromodulation 2011:179-81; discussion 182.

8. Flohil M, Verheul G, Schuuring J. Is it a relapse? Mult Scler 2009;15:523-524.

9. Koudriavtseva T, Plantone D, Renna R, Mandoj C, Giannarelli D, Mainero C. Interferon- $\beta$ therapy and risk of thrombocytopenia in multiple sclerosis patients. Neurol Sci 2015;36:2263-2268.

10. Pakulski LA, DiMarco LM. Severe vaginal bleeding associated with recombinant interferon beta-1B. Ann Pharmacother 1997;31:50-52.

11. Perlman B, Heller D, Cracchiolo B. Interferon beta-1b-induced postmenopausal bleeding in a patient with multiple sclerosis. Climacteric 2016;19:599-600.

12. Marrie RA, Reider N, Cohen J, Stuve O, Trojano M, Cutter G, Reingold S, Sorensen PS. A systematic review of the incidence and prevalence of cardiac, cerebrovascular, and peripheral vascular disease in multiple sclerosis. Mult Scler 2015;21:318-331. 